\title{
OCIMUM GRATISSIMUM L.: UMA REVISÃO DAS ATIVIDADES FARMACOLÓGICAS DA ESPÉCIE E DO SEU ÓLEO ESSENCIAL
}

\author{
Ocimum gratissimum L.: review of the pharmacological activities of the \\ species and its essential oil
}

\author{
Crisálida Machado Vilanova ${ }^{1}$, Tássio Rômulo Silva Araújo Luz ${ }^{1}$, Daniella \\ Patrícia Brandão Silveira ${ }^{1}$, Denise Fernandes Coutinho ${ }^{1}$, Emanoel Gomes de \\ Moura $^{2}$
}

${ }^{1}$ Universidade Federal do Maranhão, São Luís, Maranhão, Brasil.

${ }^{2}$ Universidade Estadual do Maranhão, São Luís, Maranhão, Brasil.

\section{Resumo}

Introdução: Ocimum gratissimum L. (alfavaca) é uma herbácea pertencente à Relação Nacional de Plantas Medicinais de Interesse ao Serviço Único de Saúde e muito utilizada na fitoterapia e por comunidades tradicionais brasileiras para tratamento de diversos males. Objetivo: Sistematizar e identificar as principais atividades farmacológicas cientificamente comprovadas e componentes químicos responsáveis pelas propriedades biológicas. Materiais e métodos: Foi realizada uma revisão bibliográfica em bases de dados de periódicos e compiladas as informações sobre as propriedades farmacológicas, parte da planta utilizada, modo de uso e meios de extração dos metabólitos secundários dessa espécie. Resultados: O óleo essencial das folhas dessa espécie é o mais empregado nos estudos farmacológicos, destacando-se suas ações antimicrobianas (de amplo espectro contra bactérias Gram positivas e negativas e fungos). Esse vegetal, de modo geral, tem intensa atividade antioxidante, a qual inclusive é considerada a responsável por outras propriedades biológicas atribuídas à alfavaca. Conclusão: Apesar de suas várias propriedades farmacológicas cientificamente comprovadas, o uso prolongado dessa planta deve ser evitado ou monitorado pelos riscos de toxicidade.

Palavras-chave: Atividade biológica; Planta medicinal; Compostos aromáticos. 


\section{Abstract}

Introduction: Ocimum gratissimum L. (clove basil) is a herbaceous belonging to the National Relation of Medicinal Plants of Interest to Unified Health System and widely used in phytotherapy and by traditional Brazilian communities for the treatment of various diseases. Objective: To systematize and identify the main scientifically proven pharmacological activities and chemical components responsible for biological properties. Material and methods: A bibliographic review was carried out in databases of periodicals and compiled the information on the pharmacological properties, part of the plant used, mode of use and means of extraction of the secondary metabolites of this species. Results: The essential oil of the leaves of this species is the most used in the pharmacological studies, highlighting its antimicrobial actions (of broad spectrum against Gram positive and negative bacteria and fungi). This vegetable in general has intense antioxidant activity, which is also considered responsible for other biological properties attributed to clove basil. Conclusions: Despite its various scientifically proven pharmacological properties, prolonged use of this plant should be avoided or monitored for the risks of toxicity.

Keywords: Biological activity; Medicinal plant; Aromatic compounds.

\section{Introdução}

A espécie vegetal, cultivada ou não, utilizada com propósitos terapêuticos e/ou profiláticos é definida pela legislação vigente no Brasil como uma planta medicinal ${ }^{1}$. O uso de plantas medicinais é uma prática popular muito difundida em todo o Brasil, que é detentor de um rico conhecimento tradicional associado às plantas ${ }^{2}$.

Em razão desse amplo uso tradicional de plantas medicinais, o Ministério da Saúde brasileiro tem incentivado o uso racional de vegetais com fins terapêuticos e seus produtos, incluindo a produção agrícola sustentável desses vegetais, por meio da Política Nacional de Plantas Medicinais e Fitoterápicos $^{3}$. A partir daí várias legislações e recomendações foram elaboradas no Brasil, objetivando a implantação da fitoterapia racional no território brasileiro, destacando-se a "Relação Nacional de Plantas Medicinais de Interesse ao SUS" (RENISUS), que consiste em 71 espécies vegetais de interesse do Ministério da Saúde para o desenvolvimento de pesquisas que levem a produção de produtos que possam ser utilizadas no Serviço Único de Saúde (SUS). A prioridade é para espécies nativas que possam ser cultivadas em pelo menos uma das regiões do país e que permitam a utilização terapêutica para tratamento das doenças mais comuns dos brasileiros ${ }^{4}$.

Dentre as espécies vegetais do RENISUS, destacase Ocimum gratissimum L., uma planta arbustiva eudicotiledônea, pertencente à família Lamiaceae, que é utilizada no alívio de diversas enfermidades por comunidades tradicionais do Brasil, onde se encontra distribuída em todas as regiões do país ${ }^{5}$.

Essas comunidades empregam principalmente as folhas dessa espécie nos tratamentos de febre, sinusite, diarreia, cólicas menstruais, transtornos do sistema nervoso, doenças genitourinárias ${ }^{6}$, sintomas de gripe $^{7,8}$, indisposição ${ }^{9}$ e como calmante ${ }^{7}$, diurético e antimicótico $^{10}$. Além disso, $O$. gratissimum se sobressai pelo seu emprego na fitoterapia, principalmente em função do óleo essencial presente em suas folhas ${ }^{11,12}$.

O termo óleo essencial se refere ao extrato vegetal obtido por vapor ou hidrodestilação ${ }^{13}$, em que se constitui em uma mistura complexa de compostos orgânicos voláteis de baixo peso molecular produzidos pelo vegetal ${ }^{14}$. Os óleos essenciais são um dos produtos naturais mais importantes derivados das plantas devido às suas diversas propriedades biológicas e usos medicinais ${ }^{15}$, amplamente utilizados nas indústrias cosméticas ${ }^{16}$, alimentícia e farmacêutica ${ }^{15}$.

Considerando-se a importância dessa planta observada pelos estudos etnofarmacológicos e sua presença na Relação Nacional de Plantas Medicinais de Interesse ao SUS - Renisus ${ }^{4}$, este trabalho teve por objetivo compilar as atividades farmacológicas de $O$. gratissimum comprovadas cientificamente e de modo especial ao seu óleo essencial.

\section{Metodologia}

A pesquisa foi realizada em abril de 2018, nas bases de dados do Portal de Periódicos da Coordenação de Aperfeiçoamento de Pessoal de Nível Superior (CAPES) e da Biblioteca Virtual em Saúde utilizando como descritor o nome científico da espécie vegetal, o termo "ocimum gratissimum", indexado no DeCS (Descritores em Ciências da Saúde). Foram excluídos os estudos que não estivessem relacionados aos objetivos da pesquisa, os sem indicação clara da parte da planta e o solvente utilizados na extração, opiniões de autores, revisões e os estudos repetidos. Foram incluídos todos os estudos de atividades biológicas com $O$. gratissimum, in vitro e in vivo. 


\section{Resultados}

Foram encontrados 1.582 artigos datados de 1930 a 2018. Após seleção e exclusões restou um total de 100 artigos disponíveis na íntegra, publicados entre os anos de 1999 a 2018, os quais foram analisados e catalogados segundo suas propriedades farmacológicas. Foi dada uma atenção especial aos estudos de óleo essencial, os quais foram analisados separadamente dos demais em função de sua importância e do volume de artigos encontrados.

\section{Atividade antibacteriana de $O$. gratissimum}

Ocimum gratissimum tem atividade antibacteriana de amplo espectro, destacando-se na literatura a ação bacteriostática das folhas dessa espécie contra as bactérias Bacillus subtilis (Gram positiva) e Escherichia coli (Gram negativa) (Tabela 1), com efeito potencializador dos efeitos da norfloxacina ${ }^{17}$.

O óleo essencial das folhas de O. gratissimum predomina nos estudos microbiológicos, com ação bacteriostática e bactericida, principalmente contra a bactéria Gram positiva Staphylococcus aureus e contra as bactérias Gram negativas Escherichia coli, Proteus mirabilis e Pseudomonas aeruginosa (Tabela 2).

Outrossim, o óleo essencial das folhas desse vegetal intensifica os antimicrobianos ciprofloxacino, ampicilina e septrina ${ }^{35}$, o que demonstra o potencial de $O$. gratissimum como agente antisséptico em formulações de uso tópico contendo o óleo essencial ${ }^{36}$, inclusive, atribuindo-se ao eugenol a responsabilidade por essa atividade no óleo ${ }^{38}$.

Organismos Gram positivos (incluindo bactérias dos gêneros Staphylococcus, Streptococcus e Enterococcus) estão entre as causas bacterianas mais comuns de infecção clínica, devido principalmente à sua associação com um espectro diversificado de patologias, variando de infecções leves da pele e dos tecidos moles à sepse sistêmica e meningite com risco de morte ${ }^{42}$. Entretanto, é preocupante a crescente resistência antibacteriana. Por esxemplo, a resistência antimicrobiana à bactérias Gram-negativas atingiu um nível crítico, onde as opções de tratamento tornaramse extremamente limitadas para alguns tipos de infecções. A resistência de Escherichia coli a agentes orais, como sulfametoxazol-trimetoprim e fluoroquinolonas, corroeu a utilidade desses antibióticos, deixando poucas opções para o tratamento de infecções do trato urinário em serviços de saúde e comunidades. Assim como a resistência aos carbapenêmicos, que aumentou na última década entre Pseudomonas aeruginosa, Acinetobacter baumannii, Klebsiella pneumoniae e outros. Com isso, as infecções sistêmicas desses organismos têm acarretado uma mortalidade inaceitavelmente alta, de até $50 \%$, devido à falta de regimes terapêuticos eficazes $^{43}$. Assim, a necessidade de antimicrobianos com novos espectros de atividade principalmente em função da crescente resistência antibacteriana, contribui para que $O$. gratissimum possa figurar como um recurso terapêutico eficaz contra infecções em razão de suas propriedades antibacterianas de amplo espectro.

\section{Atividade antifúngica de $O$. gratissimum}

A atividade fungicida dessa planta também já foi comprovada em pesquisas com extratos aquosos, etanólicos e metanólicos, principalmente de suas folhas e da parte aérea (Tabela 3). Alguns desses fungos são fitopatógenos, mas podem provocar toxicidade e infecções oportunistas em humanos, especialmente em pacientes imunodeficientes, como: Aspergillus flavus, Aspergillus niger ${ }^{45,46}$, Aspergillus tamarii $^{47}$, Bipolaris sorokiniana ${ }^{48}$, Botryosphaeria rhodina $^{49}$, Cladosporium sphaerospermum ${ }^{45,49}$ Colletotrichum gloeosporioides ${ }^{50-52}, \quad$ Fusarium compacticum $^{53,54}$, Fusarium oxysporum ${ }^{45}$, Fusarium proliferatum $^{46}$, Penicillium citrinum $^{46}$, Penicillium oxalicum $^{55}$, Rhizopus nigricans ${ }^{45}$ e Rhizopus oryzae ${ }^{56}$.

A atividade fungicida do óleo essencial de $O$. gratissimum também já foi demonstrada (Tabela 4). Frisa-se, entretanto, que alguns desses fungos são essencialmente fitopatógenos e que sua importância está no fato de serem considerados patógenos oportunistas em humanos debilitados, como é o caso dos fungos: Alternaria sp. ${ }^{45,64}$, Aspergillus flavus, Aspergillus niger ${ }^{44,45}$, Aspergillus ochraceus ${ }^{46}$, Botryosphaeria rhodina ${ }^{48}, \quad$ Colletotrichum gloeosporioides $^{50-52}$, Penicillium chrysogenum $^{45}$, Penicillium expansum $^{65}$, Penicillium verrucosum ${ }^{46}$ e Rhizoctonia $\mathrm{sp}^{45}$.

\section{Atividade inseticida de $O$. gratissimum}

As folhas dessa planta em extrato etanólico apresentam ação repelente e eficácia adulticida contra Anopheles gambiae ${ }^{74}$ e em estudos com extratos hexânico, metanólico e em acetato de etila, demonstraram eficácia contra insetos vetores da filariose, Culex gelidus e Culex quinquefasciatus, tanto na fase de larva quanto adulta desses insetos ${ }^{75}$. O óleo essencial das folhas de $O$. gratissimum exibe, também, atividade repelente ${ }^{76-78}$, com ação contra o vetor secundário de viroses como dengue, Aedes albopictus Skuse $^{79}$ em sua fase de larva.

\section{Atividade antiprotozoária de $O$. gratissimum}

Ocimum gratissimum possui também atividade contra protozoários causadores de algumas das doenças endêmicas que mais preocupam a saúde pública do Brasil: leishmaniose e malária. A ação contra os protozoários Leishmania chagasi, causador da leishmaniose visceral (calazar) e Leishmania amazonenses, agente etiológico da leishmaniose cutânea foi demonstrada pelo extrato metanólico das folhas de $O$. gratissimum $^{59}$; enquanto que a atividade antiparasitária contra Plasmodium falciparum, causador da malária, foi exibida pelas folhas dessa espécie vegetal em extratos hexânico ${ }^{80}$, metanólico ${ }^{80,81}$, etanólico ${ }^{82}$ e em acetato de etila ${ }^{80}$. 
Ocimum gratissimum 1.

TABELA 1 - Micro-organismos sensíveis à espécie vegetal Ocimum gratissimum L.

\begin{tabular}{|c|c|c|c|c|}
\hline Micro-organismo & Extrato & Parte usada & Ação & Referência \\
\hline \multicolumn{5}{|l|}{ Gram positivo } \\
\hline \multirow[t]{10}{*}{ Bacillus subtilis } & EM & $\mathrm{F}$ & BT & 18 \\
\hline & EA & $\mathrm{F}$ & BT & $19-21$ \\
\hline & EM & $\mathrm{F}$ & BT & 22 \\
\hline & $\mathrm{EH}$ & $\mathrm{F}$ & $\mathrm{BT}$ & 17 \\
\hline & $\mathrm{EE}$ & $\mathrm{F}$ & BT & $19,21,23,24$ \\
\hline & & $\mathrm{PA}$ & BT & 25 \\
\hline & $\mathrm{DC}$ & $\mathrm{F}$ & BT & 23 \\
\hline & & PA & BT & 26 \\
\hline & $\mathrm{HA}$ & PA & BT & 26 \\
\hline & $\mathrm{AL}$ & PA & BT & 26 \\
\hline \multirow{2}{*}{$\begin{array}{l}\text { Streptococcus } \\
\text { faecalis }\end{array}$} & EA & $\mathrm{F}$ & $\mathrm{BT}$ & 21 \\
\hline & $\mathrm{EE}$ & $\mathrm{F}$ & BT & 21 \\
\hline $\begin{array}{l}\text { Streptococcus } \\
\text { pneumoniae }\end{array}$ & $\mathrm{EE}$ & $\mathrm{F}$ & $\mathrm{BT}$ & 24 \\
\hline
\end{tabular}

Gram negativo

\begin{tabular}{|c|c|c|c|c|}
\hline & EM & $\mathrm{PA}$ & $\mathrm{BT}$ & 27 \\
\hline $\begin{array}{l}\text { Enterobacter } \\
\text { cloacae }\end{array}$ & $\mathrm{EM}$ & $\mathrm{PA}$ & $\mathrm{BT}$ & 27 \\
\hline \multirow[t]{10}{*}{ Escherichia coli } & EA & $\mathrm{F}$ & BT & $19-21$ \\
\hline & EM & $\mathrm{F}$ & $\mathrm{BT}$ & 18 \\
\hline & & $\mathrm{PA}$ & $\mathrm{BT} / \mathrm{BC}$ & 27 \\
\hline & $\mathrm{EE}$ & $\mathrm{F}$ & BT & $19,21,23,24$ \\
\hline & $\mathrm{EE}$ & $\mathrm{F}$ & BT & $19,21,23,24$ \\
\hline & & $\mathrm{PA}$ & $\mathrm{BT}$ & 25 \\
\hline & $\mathrm{DC}$ & $\mathrm{F}$ & BT & 23 \\
\hline & & $\mathrm{PA}$ & $\mathrm{BT}$ & 26 \\
\hline & HA & $\mathrm{PA}$ & BT & 26 \\
\hline & $\mathrm{AL}$ & $\mathrm{PA}$ & $\mathrm{BT}$ & 26 \\
\hline \multirow{2}{*}{$\begin{array}{l}\text { Klebsiella } \\
\text { pneumonia }\end{array}$} & $\mathrm{EE}$ & $\mathrm{PA}$ & $\mathrm{BT}$ & 25 \\
\hline & EM & $\mathrm{PA}$ & BT & 27 \\
\hline
\end{tabular}




\begin{tabular}{|c|c|c|c|c|}
\hline Micro-organismo & Extrato & Parte usada & Ação & Referência \\
\hline $\begin{array}{l}\text { Neisseria } \\
\text { gonorrhoeae }\end{array}$ & $\mathrm{EE}$ & PA & BT & 25 \\
\hline Proteus mirabilis & $\mathrm{EE}$ & $\mathrm{F}$ & BT & 24 \\
\hline \multirow{3}{*}{$\begin{array}{l}\text { Pseudomonas } \\
\text { aeruginosa }\end{array}$} & EA & $\mathrm{F}$ & BT & 21 \\
\hline & $\mathrm{EE}$ & $\mathrm{F}$ & BT & 21,24 \\
\hline & & PA & $\mathrm{BT}$ & 25 \\
\hline \multirow[t]{2}{*}{ Salmonela sp. } & $\mathrm{EE}$ & $\mathrm{F}$ & BT & 23,24 \\
\hline & DC & $\mathrm{F}$ & BT & 23 \\
\hline \multirow{3}{*}{$\begin{array}{l}\text { Salmonella } \\
\text { enteritidis }\end{array}$} & DC & PA & BT & 26 \\
\hline & HA & PA & BT & 26 \\
\hline & $\mathrm{AL}$ & PA & BT & 26 \\
\hline $\begin{array}{l}\text { Salmonella } \\
\text { paratyphi }\end{array}$ & EM & $\mathrm{F}$ & BT & 22 \\
\hline \multirow[t]{2}{*}{ Salmonella typhi } & EM & $\mathrm{F}$ & BT & 22 \\
\hline & $\mathrm{EE}$ & PA & BT & 25 \\
\hline \multirow[t]{2}{*}{ Shigella sp. } & $\mathrm{EE}$ & $\mathrm{F}$ & BT & 23 \\
\hline & DC & $\mathrm{F}$ & BT & 23 \\
\hline Vibrio cholerae & $\mathrm{EE}$ & PA & BT & 25 \\
\hline $\begin{array}{l}\text { Providencia } \\
\text { stuartii }\end{array}$ & EM & PA & BT & 27 \\
\hline \multirow{2}{*}{$\begin{array}{l}\text { Vibrio } \\
\text { alglinolyticus }\end{array}$} & EA & $\mathrm{F}$ & $\mathrm{BT} / \mathrm{BC}$ & 28 \\
\hline & ET & $\mathrm{F}$ & $\mathrm{BT} / \mathrm{BC}$ & 28 \\
\hline \multirow[t]{2}{*}{ Vibrio fluvialis } & EA & $\mathrm{F}$ & $\mathrm{BT} / \mathrm{BC}$ & 28 \\
\hline & ET & $\mathrm{F}$ & $\mathrm{BT} / \mathrm{BC}$ & 28 \\
\hline \multirow[t]{2}{*}{ Vibrio mimicus } & EA & $\mathrm{F}$ & $\mathrm{BT} / \mathrm{BC}$ & 28 \\
\hline & ET & $\mathrm{F}$ & $\mathrm{BT} / \mathrm{BC}$ & 28 \\
\hline \multirow{2}{*}{$\begin{array}{l}\text { Vibrio } \\
\text { parahaemolyticus }\end{array}$} & EA & $\mathrm{F}$ & $\mathrm{BT} / \mathrm{BC}$ & 28 \\
\hline & ET & $\mathrm{F}$ & $\mathrm{BT} / \mathrm{BC}$ & 28 \\
\hline \multirow{2}{*}{ Vibrio vulnificus } & EA & $\mathrm{F}$ & $\mathrm{BT} / \mathrm{BC}$ & 28 \\
\hline & ET & $\mathrm{F}$ & $\mathrm{BT} / \mathrm{BC}$ & 28 \\
\hline
\end{tabular}

Legenda: $\mathrm{AL}=$ alcoolatura; $\mathrm{DC}=$ decocto; $\mathrm{HA}=$ hidroalcoolatura; $\mathrm{EE}$ = extrato etanólico; $\mathrm{EA}$ = extrato aquoso; EM = extrato metanólico; $\mathrm{EH}$ = extrato hexânico; $\mathrm{ET}$ = extrato acetônico; $\mathrm{F}$ = folha; $\mathrm{PA}=$ parte aérea; $\mathrm{BT}=$ bacteriostático; $\mathrm{BC}=$ bactericida. 
Ocimum gratissimum 1.

TABELA 2 - Bactérias sensíveis ao óleo essencial de Ocimum gratissimum L. (Fonte: Própria - 2018)

\begin{tabular}{|c|c|c|c|}
\hline Micro-organismo & Parte usada & Ação & Referência \\
\hline \multicolumn{4}{|l|}{ Gram positivo } \\
\hline \multirow[t]{2}{*}{ Bacillus cereus } & $\mathrm{F}$ & BT & 29 \\
\hline & I & $\mathrm{BT} / \mathrm{BC}$ & 30 \\
\hline Bacillus subtilis & PA & BT & 31 \\
\hline Bacillus sp. & $\mathrm{F}$ & BT & 32 \\
\hline Corynebacterium glutamicum & $\mathrm{F}$ & BT & 29 \\
\hline \multirow{2}{*}{ Enterococcus faecalis } & $\mathrm{F}$ & BT & 29 \\
\hline & I & $\mathrm{BT} / \mathrm{BC}$ & 30 \\
\hline \multirow[t]{3}{*}{ Micrococcus luteus } & $\mathrm{F}$ & $\mathrm{BT}$ & 18 \\
\hline & $\mathrm{F}$ & $\mathrm{BC}$ & 33 \\
\hline & PA & BT & 31 \\
\hline Micrococcus flavus & PA & BT & 31 \\
\hline \multirow[t]{6}{*}{ Staphylococcus aureus } & $\mathrm{F}$ & BT & $29,32,34,35$ \\
\hline & & $\mathrm{BC}$ & $33,36,37$ \\
\hline & & $\mathrm{BT} / \mathrm{BC}$ & 38 \\
\hline & I & $\mathrm{BT} / \mathrm{BC}$ & 30 \\
\hline & PA & BT & 31 \\
\hline & PA & BT & 25 \\
\hline \multirow[t]{2}{*}{ Staphylococcus epidermidis } & $\mathrm{F}$ & BT & 29 \\
\hline & PA & BT & 31 \\
\hline Staphylococcus faecalis & $\mathrm{PA}$ & $\mathrm{BT}$ & 31 \\
\hline \multicolumn{4}{|l|}{ Gram negativo } \\
\hline \multirow[t]{2}{*}{ Enterobacter aerogenes } & $\mathrm{F}$ & BT & 39 \\
\hline & PA & BT & 31 \\
\hline \multirow[t]{6}{*}{ Escherichia coli } & $\mathrm{F}$ & BT & $18,29,32,34,35,39$ \\
\hline & & $\mathrm{BC}$ & 37 \\
\hline & & $\mathrm{BT} / \mathrm{BC}$ & 38 \\
\hline & I & $\mathrm{BT} / \mathrm{BC}$ & 30 \\
\hline & PA & $\mathrm{BT}$ & 31 \\
\hline & PI & $\mathrm{BT} / \mathrm{BC}$ & 40 \\
\hline Klebsiella sp. & $\mathrm{F}$ & $\mathrm{BT} / \mathrm{BC}$ & 38 \\
\hline \multirow[t]{2}{*}{ Klebsiella pneumonia } & $\mathrm{F}$ & $\mathrm{BT}$ & 32,39 \\
\hline & PA & BT & 31 \\
\hline Morganella morganii & $\mathrm{F}$ & $\mathrm{BT}$ & 39 \\
\hline \multirow[t]{4}{*}{ Proteus mirabilis } & $\mathrm{F}$ & BT & $32,35,39$ \\
\hline & & $\mathrm{BC}$ & 33 \\
\hline & & $\mathrm{BT} / \mathrm{BC}$ & 38 \\
\hline & PA & BT & 31 \\
\hline \multirow[t]{3}{*}{ Pseudomonas aeruginosa } & $\mathrm{F}$ & $\mathrm{BT}$ & $18,32,35,38$ \\
\hline & & $\mathrm{BC}$ & 33,36 \\
\hline & PA & BT & 31 \\
\hline Salmonela sp. & $\mathrm{I}$ & $\mathrm{BT} / \mathrm{BC}$ & 30 \\
\hline Salmonela choleraesuis & I & $\mathrm{BT} / \mathrm{BC}$ & 30 \\
\hline \multirow[t]{2}{*}{ Salmonella enteritidis } & $\mathrm{F}$ & $\mathrm{BT}$ & 41 \\
\hline & & $\mathrm{BT} / \mathrm{BC}$ & 38 \\
\hline Salmonella typhi & $\mathrm{F}$ & $\mathrm{BT}$ & 32,34 \\
\hline \multirow[t]{3}{*}{ Salmonella typhimurium } & $\mathrm{F}$ & BT & 32,34 \\
\hline & & $\mathrm{BC}$ & 37 \\
\hline & PA & BT & 31 \\
\hline Shigella sp. & I & $\mathrm{BT} / \mathrm{BC}$ & 30 \\
\hline Shigella dysenteriae & $\mathrm{F}$ & BT & 18 \\
\hline \multirow{4}{*}{ Shigella flexineri } & $\mathrm{F}$ & BT & 18 \\
\hline & & $\mathrm{BC}$ & 37 \\
\hline & & $\mathrm{BT} / \mathrm{BC}$ & 38 \\
\hline & I & $\mathrm{BT} / \mathrm{BC}$ & 30 \\
\hline Vibrio cholerae & $\mathrm{F}$ & BT & 18 \\
\hline Proteus sp. & $\mathrm{F}$ & $\mathrm{BC}$ & 36 \\
\hline Proteus vulgaris & PA & BT & 31 \\
\hline Serratia marcescens & PA & $\mathrm{BT}$ & 31 \\
\hline
\end{tabular}

Legenda: $\mathrm{F}$ = folha; $\mathrm{I}=$ inflorescência; $\mathrm{PA}=$ parte aérea; $\mathrm{PI}=$ planta inteira; $\mathrm{BT}=$ bacteriostático; $\mathrm{BC}=$ bactericida . 
Ocimum gratissimum 1.

TABELA 3 - Fungos sensíveis à espécie vegetal Ocimum gratissimum L.

\begin{tabular}{|c|c|c|c|}
\hline Fungo & Preparação & Parte usada & Referência \\
\hline Aspergillus flavus* & EA & $\mathrm{F}$ & 57 \\
\hline Aspergillus niger* & EA & $\mathrm{F}$ & 57 \\
\hline Aspergillus tamarii* & EA & $\mathrm{F}$ & 57 \\
\hline Bipolaris sorokiniana* & EA & $\mathrm{F}$ & 58 \\
\hline Candida albicans & EM & $\mathrm{F}$ e FL & 59 \\
\hline Cladosporium sphaerospermum* & EA & $\mathrm{F}$ & 57 \\
\hline \multirow[t]{3}{*}{ Colletotrichum gloeosporioides* } & EA & $\mathrm{F}$ & 60,61 \\
\hline & $\mathrm{EE}$ & $\mathrm{F}$ & 61,62 \\
\hline & EM & $\mathrm{F}$ & 61 \\
\hline Cryptococcus neoformans & EM & $\mathrm{F}$ e FL & 59 \\
\hline Epidermophyton sp. & $\mathrm{EE}$ & $\mathrm{F}$ & 63 \\
\hline Fusarium compacticum* & EA & $\mathrm{F}$ & 57 \\
\hline Fusarium oxysporum* & EA & $\mathrm{F}$ & 57 \\
\hline Fusarium proliferatum* & EA & $\mathrm{F}$ & 57 \\
\hline Malassezia furfur & $\mathrm{EE}$ & $\mathrm{F}$ & 63 \\
\hline Microsporum sp. & $\mathrm{EE}$ & $\mathrm{F}$ & 63 \\
\hline Penicillium citrinum $*$ & EA & $\mathrm{F}$ & 57 \\
\hline Penicillium oxalicum* & EA & $\mathrm{F}$ & 57 \\
\hline Rhizopus nigricans* & EA & $\mathrm{F}$ & 57 \\
\hline Rhizopus oryzae* & EA & $\mathrm{F}$ & 57 \\
\hline Trichophyton sp. & $\mathrm{EE}$ & $\mathrm{F}$ & 63 \\
\hline
\end{tabular}

* Fitopatógenos oportunistas em humanos.

Fonte: Própria (2018)

Legenda: $\mathrm{EE}=$ extrato etanólico; $\mathrm{EA}$ = extrato aquoso; $\mathrm{EM}=$ extrato metanólico; $\mathrm{F}=$ folha; $\mathrm{FL}$ = flor.

TABELA 4 - Fungos sensíveis ao óleo essencial de Ocimum gratissimum L.

Fungo $\quad$ Parte usada $\quad$ Referência

\begin{tabular}{|c|c|c|}
\hline Alternaria sp.* & PA & 66 \\
\hline Aspergillus flavus* & $\mathrm{F}$ & 67,68 \\
\hline Aspergillus fumigatus & $\mathrm{PA}$ & 31,68 \\
\hline Aspergillus niger* & PA & 31,66 \\
\hline Aspergillus ochraceus* & $\mathrm{F}$ & 69 \\
\hline Botryosphaeria rhodina* & PA & 66 \\
\hline Candida albicans & $\mathrm{F}$ & $32,33,35,68,70$ \\
\hline Candida parapsilosis & $\mathrm{F}$ & 70 \\
\hline Candida tropicalis & $\mathrm{F}$ & 70 \\
\hline Colletotrichum gloeosporioides* & PA & 60 \\
\hline Cryptococcus neoformans & $\mathrm{F}$ & 71 \\
\hline Penicillium chrysogenum* & PA & 31,66 \\
\hline Penicillium expansum* & $\mathrm{F}$ & $69,72,73$ \\
\hline Penicillium verrucosum* & $\mathrm{F}$ & 69 \\
\hline Rhizoctonia sp* & PA & 66 \\
\hline
\end{tabular}

* Fitopatógenos oportunistas em humanos.

Fonte: Própria (2018)

Legenda: $\mathrm{F}=$ folha; $\mathrm{PA}=$ parte aérea 
Além disso, $O$. gratissimum foi eficiente contra subespécies do protozoário causador da doença do sono: Trypanosoma brucei rhodesiense, que se mostrou sensível às folhas em extratos hexânico, metanólico e em acetato de etila ${ }^{83}$; e Trypanosoma brucei brucei, sensível às folhas desse vegetal em extrato aquoso ${ }^{84} \mathrm{e}$ em extrato etanólico ${ }^{85}$.

O óleo essencial das folhas de O. gratissimum também demonstrou atividade antiprotozoária contra: Trypanosoma cruzi, agente etiológico da doença de Chagas ${ }^{86}$; Plasmodium berghei, causador da malária ${ }^{87}$; e Leishmania chagasi $^{88}$ e Leishmania amazonenses ${ }^{89}$, agentes etiológicos da leishmaniose visceral (calazar) e leishmaniose cutânea, respectivamente. O óleo essencial da parte aérea desse vegetal demonstrou eficiência ainda contra o protozoário causador da doença do sono, Trypanosoma brucei brucei ${ }^{85}$.

\section{Atividade antioxidante de $O$. gratissimum}

Ocimum gratissimum possui uma forte atividade antioxidante, o que foi exibido nas pesquisas com extrato aquoso do caule desse vegetal ${ }^{90}$ e com extratos etanólico ${ }^{91,92}$, aquoso ${ }^{90,93}$, metanólico ${ }^{94}$, clorofórmico ${ }^{96}$ e hexânico ${ }^{93}$ das suas folhas.

A ação antioxidante desse vegetal é atribuída a polifenois ${ }^{90,92-94,96}$, eugenol ${ }^{91}$, taninos ${ }^{97}$, flavonoides ${ }^{92-}$ ${ }_{94,97}$, carotenoides, vitamina $\mathrm{C}^{93}$, esteroides, terpenos e alcaloides $^{94}$.

Inclusive, a atividade hepatoprotetora dessa espécie vegetal é atribuída à propriedade antioxidante dos compostos fenólicos desse vegetal, como demonstrado por estudos com extrato aquoso das folhas ${ }^{98,99} \mathrm{e}$ com extratos metanólicos das folhas ${ }^{100} \mathrm{e}$ da parte aérea ${ }^{101,102}$. Gupta et al. ${ }^{103}$ também citam o efeito hepatoprotetor das folhas de $O$. gratissimum em extrato metanólico e o atribuem à propriedade antioxidante dos flavonoides, com indicação de uma possível aplicação de seus extratos foliares na melhoria da lesão hepática. O extrato aquoso das folhas dessa espécie vegetal tem potencial de uso para a prevenção e tratamento de hepatopatias, como fibrose hepática ${ }^{104}$, e como adjuvante terapêutico na toxicidade da cisplatina, um agente antineoplásico citotóxico ${ }^{105}$.

A atividade antioxidante é considerada a responsável por outras propriedades exibidas por $O$. gratissimum, como: protetor de lesões cerebrais, como isquemia cerebral, pelo extrato etanólico da sua parte aérea ${ }^{106}$; redutor da pressão sanguínea em estudos com extrato clorofórmico ${ }^{95}$; e antimutagênica e antigenotóxica ${ }^{97}$ com extrato aquoso das folhas dessa espécie. A ação curativa de colite exibida por esse vegetal também é atribuída a propriedade antioxidante associada a anti-inflamatória ${ }^{107}$.

O óleo essencial das folhas de O. gratissimum também demonstrou potencial antioxidante e citotóxico $^{68}$ e essa atividade antioxidante, provavelmente, é responsável ainda pela inibição da tirosinase, envolvida na síntese de melanina ${ }^{108}$.
Atividade hipoglicêmica e outras atividades farmacológicas exibidas por $O$. gratissimum

Ocimum gratissimum demonstra potencial para aplicabilidade nos tratamentos de diabetes em razão do efeito hipoglicêmico de suas folhas, tanto em extratos aquosos ${ }^{109,110}$, quanto etanólicos ${ }^{109}$ e, segundo Casanova et al. ${ }^{111,112}$ quatro derivados de ácido cinâmico (ácido cafeárico, cafeico, chicórico e rosmarínico) e o flavonoide C-glucosilado (vicenina2) são os responsáveis por essa ação hipoglicêmica pela promoção do aumento da secreção de insulina. Inclusive, essa planta é capaz de reverter a anemia secundária ao Diabetes mellitus ${ }^{113}$ também pelo extrato aquoso das folhas desse vegetal.

Em relação a anemias, recentemente, o ácido ursólico, triterpeno isolado das folhas de $O$. gratissimum, demonstrou atividade também contra a falcização de hemácias, um dos sintomas característicos da anemia falciforme ${ }^{114}$.

O extrato etanólico das folhas dessa espécie vegetal provoca redução nas alterações bioquímicas, radiológicas e histopatológicas provocadas por artrite induzida por colágeno ${ }^{115}$. Há relatos também das atividades anti-inflamatória do extrato aquoso das folhas de $O$. gratissimum $^{116,117}$ e antinociceptiva com ação benéfica contra dores inflamatórias, neurogênicas e neuropáticas de suas folhas em extrato aquoso $^{116,118}$, extrato metanólico ${ }^{119}$.

Pesquisas apontam o extrato aquoso das folhas de O. gratissimum ainda como um agente antitumoral, contra: adenocarcinoma pulmonar ${ }^{120}$; tumor mamário $^{121,122}$; câncer de próstata ${ }^{123}$; osteosarcoma ${ }^{124}$.

As pesquisas indicam diversas outras propriedades farmacológicas para $O$. gratissimum: ansiolítica, em ensaios com as folhas em extrato metanólico ${ }^{125} \mathrm{e}$ extrato etanólico ${ }^{92}$; antiemética, em estudos com as folhas em extrato metanólico ${ }^{126}$; antiúlcera, em pesquisas da parte aérea em extrato etanólico ${ }^{127}$; antiurolítica, em ensaios com extrato etanólico da parte aérea dessa espécie ${ }^{128}$; anticonvulsivante de suas folhas mediante estudos em extratos aquoso ${ }^{118} \mathrm{e} \mathrm{em}$ éter de petróleo ${ }^{125}$; antidiarreica ${ }^{129}$ e protetor de tecidos cardíacos contra cirrose por hipertrofia cardíaca $^{130}$ e de cardiomiócitos do estresse oxidativo $^{131} \mathrm{em}$ análises das folhas em extrato aquoso.

Ocimum gratissimum pode ser empregada também em tratamentos fitopatológicos e veterinários. Pragas que atacam outros vegetais são combatidos igualmente por essa espécie, como o inseto Callosobruchus maculatus (caruncho-do-feijão) que demonstrou ser suscetível ao extrato etanólico ${ }^{132}$ das folhas desse vegetal. De modo semelhante, o hidrolato e o extrato aquoso $^{133}$ das folhas, assim como seu óleo essencial, demonstraram seu potencial carrapacticida em bovinos, especificamente no combate de Rhipicephalus (Boophilus) microplus ${ }^{133,134}$. Outrossim, estudos também demonstraram que o óleo essencial da parte aérea ${ }^{135,136}$ e das folhas ${ }^{137,138}$ manifestou ação anestésica em peixes, com ausência de efeitos indesejáveis e de mortalidade durante o 
manejo desses animais. Inclusive, foram comprovados os efeitos anti-helmíntico ${ }^{137}$ e de aumento da capacidade imunológica e resistência a doenças em peixes de viveiro pelo óleo essencial das folhas dessa espécie vegetal ${ }^{139}$.

Além disso, segundo Kouninki et al. ${ }^{140}$ o óleo essencial desse vegetal é um eficiente biopesticida, especialmente contra: Sitophilus zeamais Motsch (gorgulho-do-milho) ${ }^{58}$, Callosobruchus maculatus (caruncho-do-feijão) $^{141}$ e Zabrotes subfasciatus (Boheman) (Coleoptera: Bruchidae) (gorgulho-do(eijão) $)^{142}$.

Outras atividades demonstradas pelo óleo essencial das folhas de O. gratissimum foram: efeitos cardiovasculares, provocando bradicardia e hipotensão por ação vasodilatadora direta na musculatura lisa vascular do seu constituinte químico majoritário, o eugenol ${ }^{143}$; e efeitos anticonvulsivante e sedativo por ação sinérgica entre eugenol, 1,8-cineol e trans-cariofileno ${ }^{144,145}$.

\section{Toxicidade de $O$. gratissimum}

Quanto à toxicidade, pesquisas indicam que o extrato aquoso das folhas desse vegetal induz alterações neurocomportamentais com interferência no sistema colinérgico, como diminuição da frequência de locomoção ${ }^{146}$, e hematológicas com discrasias sanguíneas de eritrócitos, plaquetas e leucócitos ${ }^{147}$.

O consumo prolongado das suas folhas in natura provoca redução significativa de parâmetros hematológicos (como a hemoglobina) e bioquímicos, como proteína sérica, colesterol e peroxidação lipídica $^{148}$. Em relação a essa ação de $O$. gratissimum sobre o colesterol, é importante frisar que apesar do efeito cardiovascular benéfico gerado pela diminuição do nível sérico dessa substância no organismo, há indícios de que a redução intensa dos niveis séricos de colesterol aumenta a incidência de quadros de ansiedade pela diminuição de serotonina cerebral ${ }^{149}, \mathrm{o}$ que justifica a necessidade de se evitar ou monitorar o consumo prolongado dessa planta (especialmente in natura).

Ademais, estudos demonstram que essa espécie vegetal provoca alterações na fertilidade masculina e feminina. Houve diminuição da fertilidade masculina em testes feitos com extrato aquoso de folhas ${ }^{150}$ e da fertilidade feminina em ensaios realizados com extrato acetônico de caule ${ }^{151}$ e extrato metanólico de folhas ${ }^{152}$ de $O$. gratisismum.

Outros estudos sobre a toxicidade dessa espécie vegetal relatam ausência de genotoxicidade, espermatoxicidade e citotoxicidade de suas folhas ${ }^{153,154}$. Contudo, Akinboro e Bakare ${ }^{153}$ sugerem uma possível atividade mutagênica do extrato aquoso das folhas de $O$. gratissimum e Hernández et al. ${ }^{154}$ citam efeitos tóxicos agudos e significativos de hepatotoxicidade e nefrotoxicidade na dose $3 \mathrm{~g} / \mathrm{kg}$ de extrato fluido das folhas dessa espécie.
Apesar de sua comprovada atividade hipoglicêmica ${ }^{109-112}$, Olabanji et al. ${ }^{155}$ sugerem, para prevenir complicações, que pacientes diabéticos evitem o uso dessa espécie em razão da presença de arsênio (As), cromo $(\mathrm{Cr})$ e cobre $(\mathrm{Cu})$ nas suas folhas acima da recomendação diária de ingesta.

Quanto a toxicidade do óleo essencial das folhas de O. gratissimum, a dose com $1,5 \mathrm{~g} / \mathrm{kg}$ de peso corporal não provoca danos estomacais e hepáticos ${ }^{156}$. Mas, o uso interno de monopreparados a base do óleo essencial das inflorescências dessa espécie para o tratamento de infeções microbianas não é aconselhado devido à toxicidade observada para Artemia salina e aos altos valores de Concentração Inibitória Mínima e Concentração Bactericida Mínima quando comparado a ampicilina, utilizada como antibiótico padrão, tendose como alternativa o emprego associado a antibióticos ou em preparações de uso tópico ${ }^{30}$, desde que se evite o emprego concomitante com estreptomicina ${ }^{35}$, amicacina e gentamicina ${ }^{157}$, por seu efeito antagonista a esses antibióticos.

Nossos resultados demonstraram o potencial de utilização dessa espécie vegetal no desenvolvimento de possíveis produtos de interesse biotecnológico, especialmente no aspecto da saúde humana. Ressaltando-se, contudo, a necessidade de trabalhos voltados para a elucidação de mecanismos de ação da maioria das atividades biológicas demonstradas por essa espécie vegetal, assim como, futuros trabalhos de integração dos campos da farmacologia, química e tecnologia farmacêutica na produção de fitomedicamentos a base de $O$. gratissimum.

\section{Conclusão}

Ocimum gratissimum L. apresenta potencial de desenvolvimento de produtos de interesse farmacêutico, com emprego no tratamento de diversas enfermidades, especialmente em função de suas propriedades antibacterianas, antifúngicas, inseticidas, antiprotozoárias, hipogliêmicas e antioxidantes, dentre outras. Entretanto, deve ser usada com critério e monitoramento pelos riscos de toxicidade associados ao uso prolongado.

\section{Declaração de conflitos de interesses}

Os autores do artigo afirmam que não houve nenhuma situação de conflito de interesse, tais como propostas de financiamento, emissão de pareceres, promoções ou participação em comitês consultivos ou diretivos, entre outras, que pudessem influenciar no desenvolvimento do trabalho.

\section{Referências}

1. BRASIL. Agência Nacional de Vigilância Sanitária. Primeiro Suplemento do Formulário de Fitoterápicos da Farmacopeia Brasileira. Brasília: Anvisa, 2018.

2. LEAL-COSTA, M. V.; TEODORO, F. S.; BARBIERI, C.; SANTOS, L. F. U.; SOUSA, A. L. 
Avaliação da qualidade das plantas medicinais comercializadas no Mercado Municipal de Campos dos Goytacazes-RJ. Revista Fitos, v. 12, n. 2, p. 127-134, 2018. 3. BRASIL. Ministério da Saúde. Política nacional de plantas medicinais e fitoterápicos. Brasília: Ministério da Saúde, 2006.

4. BRASIL. Ministério da Saúde. RENISUS-Relação nacional de plantas medicinais de interesse ao SUS. Brasília: Ministério da Saúde, 2009.

5. FLORA DO BRASIL. Lamiaceae. Disponível em: <http://floradobrasil.jbrj.gobr/reflora/floradobrasil/FB2333 2>. Acesso em: 26 fev. 2018.

6. RODRIGUES, A. P.; ANDRADE, L. H. C. Levantamento etnobotânico das plantas medicinais utilizadas pela comunidade de Inhamã, Pernambuco, Nordeste do Brasil. Revista Brasileira de Plantas Medicinais, v. 16, n. 3, p. 721-730, 2014.

7. SILVA, W. A.; FAGUNDES, N. C. A.; COUTINHO, C. A.; SOARES, A. C. M.; CAMPOS, P. V.; FIGUEIREDO, L. S. Levantamento etnobotânico de plantas medicinais na cidade de São João da Ponte-MG. Revista de Biologia e Farmácia, v. 7, n.1, p. 122-131, 2012.

8. CUNHA, M. M. C.; GONDIM, R. S. D.; BONFIM, B. F.; BATALHA JUNIOR, N. J. P.; BARROSO, W. A.; VILANOVA, C. M. Perfil etnobotânico de plantas medicinais comercializadas em feiras livres de São Luís, Maranhão, Brasil. Scientia Plena, v. 11, n. 12, p. 121202-1, 2015.

9. NETO, F. R. G.; ALMEIDA, G. S. S. A.; JESUS, N. G.; FONSECA, M. R. Estudo Etnobotânico de plantas medicinais utilizadas pela Comunidade do Sisal no município de Catu, Bahia, Brasil. Revista Brasileira de Plantas Medicinais, v. 16, n. 4, p. 856-865, 2014.

10. ALVES, G. S. P.; POVH, J. A. Estudo etnobotânico de plantas medicinais na comunidade de Santa Rita, Ituiutaba MG. Biotemas, v. 26, n. 3, p. 231-242, 2013.

11 . LORENZI, H.; MATOS, F. J. A. Plantas medicinais do Brasil: nativas e exóticas. Nova Odessa: Instituto Plantarum, 2002.

12. NEGRI, G. Diabetes melito: plantas e princípios ativos naturais hipoglicemiantes. Revista Brasileira de Ciências Farmacêuticas, v. 41, n. 2, p. 121-142, 2005.

13. ASBAHANI, A. EL; MILADI, K.; BADRI, W.; SALA, M.; ADDI, E. H. A.; CASABIANCA, H.; MOUSADIK, A. EL; HARTMANN, D.; JILALE, A.; RENAUD, F. N. R.; ELAISSARI, A. Essential oils: From extraction to encapsulation. International Journal of Pharmaceutics, v. 483, n. 1-2, p. 220-243, 2015.

14. DHIFI, W.; BELLILI, S.; JAZI, S.; BAHLOUL, N.; MNIF, W. Essential oils' chemical characterization and investigation of some biological activities: a critical review. Medicines, v. 3, n. 4, p. 25, 2016.

15. ELSHAFIE, H. S.; CAMELE, I. An overview of the biological effects of some mediterranean essential oils on human health. BioMed Research International, v. 2017, p. 1-14, 2017.

16. SARKIC, A.; STAPPEN, I. Essential oils and their single compounds in cosmetics-a critical review. Cosmetics, v. 5, n. 1, p. 1-21, 2018.

17. COUTINHO, H. D. M.; MATIAS, E. F. F.; SANTOS, K. K. A.; SANTOS, F. A. V.; MORAIS-BRAGA, M. F. B.; SOUZA, T. M.; ANDRADE, J. C.; SOUZA, C. E. S.; TINTINO, S. R.; GUEDES, G. M. M.; FALCÂO-SILVA, V. S.; SIQUEIRA-JÚNIOR, J. P.; COSTA, J. G. M. Modulation of the norfloxacin resistance in Staphylococcus aureus by Crotón campestris A. and Ocimum gratissimum L. Biomédica, v. 31, n. 4, p. 608-612, 2011.

18. SAHA, S.; DHAR, T. N.; SENGUPTA, C.; GHOSH, P. Biological activities of essential oils and methanol extracts of five Ocimum species against pathogenic bacteria. Czech Journal of Food Sciences, v. 31, n. 2, p. 194-202, 2013.

19. NWINYI, O. C.; CHINEDU, N. S.; AJANI, O. O.; IKPO, C.O.; OGUNNIRAN, K. O. Antibacterial effects of extracts of Ocimum gratissimum and Piper guineense on Escherichia coli and Staphylococcus aureus. African Journal of Food Science, v. 3, n. 3, p. 77-81, 2009.

20. ISHIWU, C. N.; UMENWANNE, C. P.; OBIEGBUNA, J. E.; UCHEGBU, N. N. In vitro assessment of anti bacterial effect of extracts of Ocimum gratissimum and Carica papaya leaves. International Journal of Applied Science and Technology, v. 4, n. 1, p. 171-177, 2014.

21. MBAJIUKA, C. S.; OBEAGU, E. I.; OCHEI, K. C.; NNADI, D. C.The antibacterial activity of leaf extracts of Ocimum gratissimum and Sida acuta. IOSR Journal of Dental and Medical Sciences, v. 13, n. 6, p. 80-85, 2014.

22. PRASANNABALAJI, N.; MURALITHARAN, G.; SIVANANDAN, R. N.; KUMARAN, S.; PUGAZHVENDAN, S. R. Antibacterial activities of some Indian traditional plant extracts. Asian Pacific Journal of Tropical Disease, v. 2, n. 1, p. S291-S295, 2012.

23. AMENGIALUE, O. O.; EDOBOR, O.; EGHAREVBA, A. P. Antibacterial activity of extracts of Ocimum gratissimum on bacteria associated with diarrhea. Bayero Journal of Pure e Applied Sciences, v. 6, n. 2, p. 143-145, 2013.

24. OMODAMIRO, O. D.; JIMOH, M. A. Antioxidant and antibacterial activities of Ocimum gratissimum. American Journal of Phytomedicine and Clinical Therapeutics, v. 3, n. 1, p. 10-19, 2015.

25. MANN, A. Phytochemical constituents and antimicrobial and grain protectant activities of clove basil (Ocimum gratissimum L.) grown in Nigeria. International Journal of Plant Research, v. 2, n. 1, p. 51-58, 2012.

26. PASSOS, M. G.; CARVALHO, H.; WIEST, J. M. Inibição e inativação in vitro de diferentes métodos de extração de Ocimum gratissimum L. ("alfavacão", "alfavaca", "alfavaca-cravo") - Labiatae (Lamiaceae), frente a bactérias de interesse em alimentos. Revista Brasileira de Plantas Medicinais, v. 11, n. 1, p. 71-78, 2009.

27. DJEUSSI, D. E.; NOUMEDEM, J. A. K.; SEUKEP, J. A.; FANKAM, A. G.; VOUKENG, I. K.; TANKEO, S. B.; NKUETE, A. H. L.; KUETE, V. Antibacterial activities of selected edible plants extracts against multidrug-resistant Gram-negative bacteria. BMC Complementary and Alternative Medicine, v. 13, n. 164, p. 1-8, 2013.

28. IGBINOSA, E. O.; IDEMUDIA, O. G. Anti-vibrio potentials of acetone and aqueous leaf extracts of Ocimum gratissimum (Linn). Tropical Journal of Pharmaceutical Research, v. 15, n. 4, p. 743-750, 2016.

29. NGASSOUM, M. B.; ESSIA-NGANG, J. J.; TATSADJIEU, L. N.; JIROVETZ, L.; BUCHBAUER, G.; ADJOUDJI, O. Antimicrobial study of essential oils of Ocimum gratissimum leaves and Zanthoxylum xanthoxyloides fruits from Cameroon. Fitoterapia, v. 74, n. 3, p. 284-287, 2003.

30. SILVA, L. L.; HELDWEIN, C. G.; REETZ, L. G. B.; HÖRNER, R.; MALLMANN, C. A.; HEINZMANN, B. M. Composição química, atividade antibacteriana in vitro e toxicidade em Artemia salina do óleo essencial das inflorescências de Ocimum gratissimum L., Lamiaceae. Revista Brasileira de Farmacognosia, v. 20, n. 5, p. 700705, 2010.

31. JOSHI, R. Chemical composition, In vitro antimicrobial and antioxidant activities of the essential oils of Ocimum gratissimum, O. sanctum and their major 
constituents. Indian Journal of Pharmaceutical Sciences, v. 75, n. 4, p. 457-461, 2013.

32. MATASYOH, L. G.; MATASYOH, J. C.; WACHIRA, F. N.; KINYUA, M. G.; MUIGAI, A. W. T.; MUKIAMA, T. K. Antimicrobial activity of essential oils of Ocimum gratissimum L. from different populations of Kenya. African Journal of Traditional, Complementary and Alternative Medicines, v. 5, n. 2, p. 187-193, 2008.

33. BONOU, J.; BABA-MOUSSA, F.; NOUMAVO, P. A.; AHOUANDJINOU, H.; ADEOTI, K.; METOGNON, I.; AKPAGANA, K.; MANSOUROU, M.; GBÉNOU, J. D.; TOUKOUROU, F.; BABA-MOUSSA, L. Composition chimique et influence de differents tweens sur le pouvoir antimicrobien des huiles essentielles de Ocimum gratissimum, Ocimum basilicum, Laurus nobilis et Melaleuca quinquenervia. European Scientific Journal, v. 12, n. 27, p. 162-171, 2016.

34. ADEBOLU, T. T.; OLADIMEJI, S. A. Antimicrobial activity of leaf extracts of Ocimum gratissimum on selected diarrhoea causing bacteria in southwestern Nigeria. African Journal of Biotechnology, v. 4, n. 7, p. 682-684, 2005.

35. NWEZE, E. I.; EZE, E. E. Justification for the use of Ocimum gratissimum $\mathrm{L}$ in herbal medicine and its interaction with disc antibiotics. BioMed Central Complementary and Alternative Medicine, v. 9 , n. 1, p. 37, 2009.

36. ORAFIDIYA, L. O.; OYEDELE, A. O.; SHITTU, A. O.; ELUJOBA, A. A.The formulation of an effective topical antibacterial product containing Ocimum gratissimum leaf essential oil. International Journal of Pharmaceutics, v. 224, n. 1-2, p. 177-183, 2001.

37. CHIMNOI, N.; REUK-NGAM, N.; CHUYSINUAN, P. KHLAYCHAN, P.; KHUNNAWUTMANOTHAM, N.; CHOKCHAICHAMNANKIT, D.; THAMNIYOM, W; KLAYRAUNG, S.; MAHIDOL, C.; TECHASAKUL, S. Characterization of essential oil from Ocimum gratissimum leaves: Antibacterial and mode of action against selected gastroenteritis pathogens. Microbial Pathogenesis, n. 118, p. 290-300, 2018.

38. NAKAMURA, C. V.; UEDA-NAKAMURA, T.; BANDO, E.; MELO, A. F. N.; CORTEZ, D. A. G.; DIAS FILHO, B. P. Antibacterial activity of Ocimum gratissimum L. essential oil. Memórias do Instituto Oswaldo Cruz, v. 94, n. 5, p. 675-678, 1999.

39. PEREIRA, R. S.; SUMITA, T. C.; FURLAN, M. R.; JORGE, A. O. C.; UENO, M. Antibacterial activity of essential oils on microorganisms isolated from urinary tract infection. Revista Saúde Pública, v. 38, n. 2, p. 326-328, 2004.

40. ADESEGUN, A. S.; SAMUEL, F. O.; ANTHONY, O. B.; NURUDEEN, O. A. Antioxidant and inhibitory properties of essential oil of Ocimum gratissimum against extracellular protease of Escherichia coli. IOSR Journal of Pharmacy, v. 3, n. 1, p. 50-55, 2013.

41. ADEOLA, S. A.; FOLORUNSO, O. S.; OKEDEYI, O. O.; OGUNGBE, B. F.; BABATIMEHIN, O. B.; THANNI, O. Z. Antioxidant and antimicrobial activities of the volatile oil of Ocimum gratissimum and its inhibition on partially purified and characterized extracellular protease of Salmonella enteritidis. American Journal of Drug Discovery and Development, n. 4, p. 180-193, 2014.

42. EADES, C.; HUGHES, S.; HEARD, K.; MOORE, L. S. Antimicrobial therapies for Gram-positive infections. Clinical Pharmacist, v. 9, n. 9, 2017.

43. DOI, Y.; BONOMO, R. A.; HOOPER, D. C. KAYE, K. S.; JOHNSON, J. R.; CLANCY, C. J.; THADEN, J. T.; STRYJEWSKI, M. E.; VAN DUIN, D.; ARLG. Gramnegative bacterial infections: research priorities, accomplishments, and future directions of the antibacterial resistance leadership group. Clinical Infectious Diseases, v. 64, n. 1, p. S30-S35, 2017.

44. DAGENAIS, T. R. T.; KELLER, N. P. Pathogenesis of Aspergillus fumigatus in Invasive Aspergillosis. Clinical Microbiology Review, v. 22, n. 3, p. 447-465, 2009.

45. MANISHA, K.; PANWAR, N. Morpho-pathological effects of isolated fungal species on human population. Scientific Reports, v. 1, n. 11, p. 1-6, 2012.

46. AL-FAKIH, A. A. Overview on the fungal metabolites involved in mycopathy. Open Journal of Medical Microbiology, v. 4, n. 1, p. 38-63, 2014.

47. SHAFII, S. M.; DONATE, G.; MANNARI, R. J.; PAYNE, W. G.; ROBSON, M. C. Diagnostic dilemmas: cutaneous fungal bipolaris infection. Wounds, v. 18, n. 1, p. 19-24, 2006

48. POUNDER, J. I.; SIMMON, K. E.; BARTON, C. A.; HOHMANN, S. L.; BRANDT, M. E.; PETTI, C. A. Discovering potential pathogens among fungi identified as nonsporulating molds. Journal of Clinical Microbiology, v. 45, n. 2 , p. 568-571, 2007.

49. YANO, S.; KOYABASHI, K.; KATO, K. Intrabronchial lesion due to Cladosporium sphaerospermum in a healthy, non-asthmatic woman. Mycoses, v. 46, n. 8, p. 348-350, 2003.

50. GUARRO, J.; SVIDZINSKI, T. E.; ZAROR, L.; FORJAZ, M. H.; GENÉ, J.; FISCHMAN, O. Subcutaneous hyalohyphomycosis caused by Colletotrichum gloeosporioides. Journal of Clinical Microbiology, v. 36, $n$. 10, p. 3060-3065, 1998.

51. OGAWA, M.; REIS, V.; GODOY, P.; MENEZES, F. G.; ENOKIHARA, M.; TOMIMORI, J. Feohifomicosis causada por Colletotrichum gloeosporioides y Alternaria infectoria en un paciente trasplantado renal. Revista Chilena de Infectología, v. 31, n. 4, p. 468-472, 2014.

52. CHO, J. C.; SHARMA, R. S.; SUTTON, D. A.; WIEDERHOLD, N. P.; SANDERS, C.; WICKES, B. L.; ESTRADA, S. J. Fungal arthritis secondary to Colletotrichum gloeosporioides. Journal of Medical Microbiology Case Reports, v. 2, n. 1, p. 1-4, 2015.

53. PINCELLI, T. P. H.; BRANDT, H. R. C.; MOTTA, A. L.; MACIEL, F. V. R.; CRIADO, P. R. Fusariose em paciente imunocomprometido: sucesso terapêutico com voriconazol. Anais Brasileiros de Dermatoogia, v. 83, n. 4, p. 331-334, 2008.

54. MIRHENDI, H.; GHIASIAN, A.; VISMER, H.; ASGARY, M.; JALALIZAND, N.; ARENDRUP, M.; MAKIMURA, K. Preliminary identification and typing of pathogenic and toxigenic Fusarium species using restriction digestion of ITS1-5.8S rDNA-ITS2 Region. Iranian Journal of Public Health, v. 39, n. 4, p. 35-44, 2010.

55. CHOWDHARY, A.; KATHURIA, S.; AGARWAL, K.; SACHDEVA, N.; SINGH, P. K.; JAIN, S.; MEIS, J. F.. Voriconazole-Resistant Penicillium oxalicum: an emerging pathogen in immunocompromised hosts. Open Forum Infectious Diseases, v. 1, n. 2, p. ofu029, 2014.

56. RIBES, J. A.; VANOVER-SAMS, C. L.; BAKER, D. J. Zygomycetes in human disease. Clinical Microbiology Reviews, v. 13, n. 2, p. 236-301, 2000.

57. BANKOLE, S. A.; SOMORIN, Y. M. Antifungal activity of extracts of Ocimum gratissimum and Aframomum danielli against moulds isolated from stored rice. 10th International Working Conference on Stored Product Protection, n. 425, p. 578-585, 2010.

58. RODRIGUES, É. A.; SCHWAN-ESTRADA, K. R. F.; STANGARLIN, J. R.; SCAPIM, C. A.; FIORI-TUTIDA, A. C. G. Potencial da planta medicinal Ocimum gratissimum no controle de Bipolaris sorokiniana em sementes de trigo. Acta Scientiarum Agronomy, v. 28, n. 2, p. 213-220, 2006. 
59. BRAGA, F. G.; BOUZADA, M. L. M.; FABRI, R. L.; MATOS, M. O.; MOREIRA, F. O.; SCIO, E.; COIMBRA, E. S. Antileishmanial and antifungal activity of plants used in traditional medicine in Brazil. Journal of Ethnopharmacology, v. 111, n. 2, p. 396-402, 2007.

60. SILVA, A. C.; SALES, N. L. P.; ARAÚJO, A. V.; JÚNIOR, C. F. C. Efeito in vitro de compostos de plantas sobre o fungo Colletotrichum gloeosporioides Penz. isolado do maracujazeiro. Ciência e Agrotecnologia, n. 33, p. 18531860,2009

61. ORJI, J. O.; NWUZO, A. C.; EJIKEUGWU, P. C.; UGBO, E. N.; MOSES, I. B.; NWAKAEZE, E. A.; NWANKWO, C. P. Antifungal activities of Ocimum gratissimum and Gongronema latifolium leaves on Colletotrichum species isolated from spoilt tomatoes. International Journal of Pharmaceutical Science Invention, v. 4, n. 5, p. 42-45, 2015.

62. ANDRADE-PINTO, J. M. A.; SOUZA, E. A.; OLIVEIRA, D. F. Use of plant extracts in the control of common bean anthracnose. Crop Protection, v. 29, n. 8, p. 838-842, 2010.

63. MBAKWEM-ANIEBO, C.; ONIANWA, O.; OKONKO, I. O. Effects of Ocimum gratissimum leaves on common dermatophytes and causative agent of Pityriasis versicolor in Rivers State, Nigeria. Journal of Microbiology Research, v. 2, n. 4, p. 108-113, 2012.

64. PASTOR, F. J.; GUARRO, J. Alternaria infections: laboratory diagnosis and relevant clinical features. Clinical Microbiology and Infection, v. 14, n. 8, p. 734-746, 2008. 65. PÁDUA, R. A. F. de; MACHINSKI JUNIOR, M. Aspectos toxicológicos e ocorrência de patulina em suco de maçã. Semina Ciências Agrárias, v. 26, n. 4, p. 535-542, 2005.

66. FARIA, T. de J.; FERREIRA, R. S.; YASSUMOTO, L.; SOUZA, J. R. P. de; ISHIKAWA, N. K.; BARBOSA, A. de M. Antifungal activity of essential oil isolated from Ocimum gratissimum L. (eugenol chemotype) against phytopathogenic fungi. Brazilian Archives of Biology and Technology, v. 49, n. 6, p. 867-871, 2006.

67. TATSADJIEU, N. L.; YAOUBA, A.; NUKENINE, E. N.; NGASSOUM, M. B.; MBOFUNG, C. M. F. Comparative study of the simultaneous action of three essential oils on Aspergillus flavus and Sitophilus zeamais Motsch. Food Control, v. 21, n. 2, p. 186-190, 2010.

68. KOUASSI, E. K.; OUATTARA, S.; SEGUIN, C.; FOURNEL, S.; FRISCH, B. Etude de quelques proprietes biologiques de Ocimum gratissimum L., une lamiaceae recoltee a Daloa (Côte d'Ivoire). European Scientific Journal, v. 14, n. 3, p. 1857 - 7881, 2018.

69. NGUEFACK, J.; DONGMO, J. B. L.; DAKOLE, C. D.; LETH, V.; VISMER, H. F.; TORP, J.; GUEMDJOM, E. F. N.; MBEFFO, M.; TAMGUE, O.; FOTIO, D.; ZOLLO, P. H. A.; NKENGFACK, A. E. Food preservative potential of essential oils and fractions from Cymbopogon citratus, Ocimum gratissimum and Thymus vulgaris against mycotoxigenic fungi. International Journal of Food Microbiology, v. 131, n. 2-3, p. 151-156, 2009.

70. OLIVEIRA, L. B. S.; BATISTA, A. H. M.; FERNANDES, F. C.; SALES, G. W. P.; NOGUEIRA, N. A. P. Atividade antifúngica e possível mecanismo de ação do óleo essencial de folhas de Ocimum gratissimum (Linn.) sobre espécies de Candida. Revista Brasileira de Plantas Medicinais, v. 18, n. 2, p. 511-523, 2016.

71. LEMOS, J. de A; PASSOS, X. S.; FERNANDES, O. de F.; PAULA, J. R. de; FERRI, P. H.; SOUZA, L. K. H. E.; LEMOS, A de A.; SILVA, M. do R. R. Antifungal activity from Ocimum gratissimum $\mathrm{L}$. towards Cryptococcus neoformans. Memórias do Instituto Oswaldo Cruz, v. 100, n. 1, p. 55-58, 2005.
72. TAMGUE, O.; BENGYELLA, L.; NGUEFACK, J.; DONGMOA, J. B. L.; DAKOLEA, C. D. Synergism and antagonism of essential oil fractions of Cymbopogon citratus, Ocimum gratissimum and Thymus vulgaris against Penicillium expansum. International Journal of Plant Pathology, v. 2, n. 2, p. 51-62, 2011.

73. NGUEFACK, J.; TAMGUE, O.; DONGMO, J. B. L.; DAKOLE, C. D.; LETH, V.; VISMER, H. F.; AMVAMZOLLO, P. H.; NKENGFACK, A. E. Synergistic action between fractions of essential oils from Cymbopogon citratus, Ocimum gratissimum and Thymus vulgaris against Penicillium expansum. Food Control, v. 23, n. 2, p. 377 383, 2012.

74. AFOLABI OJ, SIMON-OKE IA., ELUFISAN OO; ONIYA, M. O. Adulticidal and repellent activities of some botanical oils against malaria mosquito: Anopheles gambiae (Diptera: Culicidae). Beni-Suef University Journal of Basic and Applied Sciences, v. 7, n. 1, p. 135-138, 2018.

75. KAMARAJ, C.; RAHUMAN, A. A. Larvicidal and adulticidal potential of medicinal plant extracts from south India against vectors. Asian Pacific Journal of Tropical Medicine, v. 3, n. 12, p. 948-953, 2010.

76. USIP, L. P.; OPARA, K. N.; IBANGA, E. S.; ATTING, I. A. Longitudinal evaluation of repellent activity of Ocimum gratissimum (Labiatae) volatile oil against Simulium damnosum. Memórias do Instituto Oswaldo Cruz, v. 101, n. 2, p. 201-205, 2006.

77. OPARAOCHA, E. T.; IWU, I.; AHANAKUC, J. E. Preliminary study on mosquito repellent and mosquitocidal activities of Ocimum gratissimum (L.) grown in eastern Nigeria. Journal of Vector Borne Diseases, v. 47, n. 1, p. 45-50, 2010.

78. NGUEMTCHOUIN, M. G. M.; NGASSOUM, M. B.; CHALIER, P.; KAMGA, R.; NGAMO, L. S. T.; CRETIN, M. Ocimum gratissimum essential oil and modified montmorillonite clay, a means of controlling insect pests in stored products. Journal of Stored Products Research, n. 52, p. 57-62, 2013.

79. SUMITHA, K. V.; THOPPIL, J. E. Larvicidal efficacy and chemical constituents of $O$. gratissimum L. (Lamiaceae) essential oil against Aedes albopictus Skuse (Diptera: Culicidae). Parasitology Research, v. 115, n. 2, p. 673-680, 2016.

80. ABIODUN, O.; GBOTOSHO, G.; AJAIYEOBA, E.; HAPPI, T.; FALADE, M.; WITTLIN, S.; SOWUNMI, A.; BRUN, R.; ODUOLA, A. In vitro antiplasmodial activity and toxicity assessment of some plants from Nigerian ethnomedicine. Pharmaceutical Biology, v. 49, n. 1, p. 914, 2011.

81. KAMARAJ, C.; KAUSHIK, N. K.; MOHANAKRISHNAN, D.; ELANGO, G.; BAGAVAN, A.; ZAHIR, A. A.; RAHUMAN, A. A.; SAHAL, D. Antiplasmodial potential of medicinal plant extracts from Malaiyur and Javadhu hills of South India. Parasitology Research, v. 111, n. 2, p. 703-715, 2012.

82. TABA, K. M.; PAULUS, J.; KAYEMBE, J. S. Malaria: novel plant remedies show great promise in treating the deadly disease. Global Journal of Research on Medicinal Plants e Indigenous Medicine, v. 1, n. 3, p. 6268,2012

83. ABIODUN, O. O.; GBOTOSHO, G. O.; AJAIYEOBA, E. O.; BRUN, R.; ODUOLA, A. M. Antitrypanosomal activity of some medicinal plants from Nigerian ethnomedicine. Parasitology Research, v. 110, n. 2, p. 521-526, 2012.

84. ADAMU, M.; NWOSU, C. O.; AGBEDE, R. I. S. AntiTrypanosomal effects of aqueous extract of Ocimum gratissimum (Lamiaceae) leaf in rats infected with Trypanosoma brucei brucei. African Journal of 
Traditional, Complementary and Alternative Medicines, v. 6, n. 3, p. 262-267, 2009.

85. KPADONOU-KPOVIESSI, B. G. H.; KPOVIESSI, S. D. S.; LADEKAN, E.Y.; GBAGUIDI, F.; FRÉDÉRICH, M.; MOUDACHIROU, M.; QUETIN-LECLERCQ, J.; ACCROMBESSI, G.C.; BERO, J. In vitro antitrypanosomal andantiplasmodial activities of crude extracts and essential oils of Ocimum gratissimum Linn from Benin and influence of vegetative stage. Journal of Ethnopharmacology, v. 155, n. 3, p. 1417-1423, 2014.

86. BORGES, A. R.; AIRES, J. R. de A.; HIGINO, T. M. M.; MEDEIROS, M. das G. F. de; CITÓ, A. M. G. L; LOPES, J. A. D.; FIGUEIREDO, R. C. B. Q de. Trypanocidal and cytotoxic activities of essential oils from medicinal plants of Northeast of Brazil. Experimental Parasitology, v. 132, n. 2, p. 123-128, 2012.

87. TCHOUMBOUGNANG, F.; ZOLLO, P. H. A.; DAGNE, E.; MEKONNEN. In vivo antimalarial activity of essencial oils from Cymbopogon citratus and Ocimum gratissimum on mice infected with Plasmodium berghei. Planta Medica, v. 71, n. 1, p. 20-23, 2005.

88. OLIVEIRA, V. C. S.; MOURA, D. M. S.; LOPES, J. A. D.; ANDRADE, P. P. de; SILVA, N. H. da; FIGUEIREDO, R. C. B. Q. Effects of essential oils from Cymbopogon citratus (DC) Stapf., Lippia sidoides Cham., and Ocimum gratissimum L. on growth and ultrastructure of Leishmania chagasi promastigotes. Parasitology Research, v. 104, n. 5, p. 1053-1059, 2009.

89. UEDA-NAKAMURA, T.; MENDONÇA-FILHO, R. R.; MORGADO-DIAZ, J. A.; MAZA, P. K.; FILHO, B. P. D.; CORTEZ, D. A. G.; ALVIANO, D. S.; ROSA, M. S. S.; LOPES, A. H. C. S.; ALVIANO, C. S.; NAKAMURA, C. V. Antileishmanial activity of eugenol-rich essential oil from Ocimum gratissimum. Parasitology International, v. 55, n. 2, p. 99-105, 2006.

90. CHIU, Y. W.; LO, H. J.; HUANG, H. J.; CHAO, P. Y.; HWANG, J. M.; HUANG, P. Y.; HUANG, S. J.; LIU, J. Y.; LAI, T. J. The antioxidant and cytoprotective activity of Ocimum gratissimum extracts against hydrogen peroxideinduced toxicity in human HepG2 cells. Journal of Food and Drug Analysis, v. 21, n. 3, p. 253-260, 2013.

91. PEREIRA, C. A. M.; MAIA, J. F. Estudo da atividade antioxidante do extrato e do óleo essencial obtidos das folhas de alfavaca (Ocimum gratissimum L.). Ciência e Tecnologia de Alimentos, v. 27, n. 3, p. 624-632, 2007.

92. VENUPRASAD, M. P.; KUMAR KANDIKATTU, H.; RAZACK, S.; KHANUM, F. Phytochemical analysis of Ocimum gratissimum by LCESI-MS/MS and its antioxidant and anxiolytic effects. South African Journal of Botany, n. 92, p. 151-158, 2014. 93. OBOH, G.; RADDATZ, H.; HENLE, T. Antioxidant properties of polar and non-polar extracts of some tropical green leafy vegetables. Journal of the Science of Food and Agriculture, v. 88, n. 14, p. 2486-2492, 2008.

94. AKINMOLADUN, A. C.; OBUOTOR, E. M.; FAROMBI, E. O. Evaluation of antioxidant and free radical scavenging capacities of some nigerian indigenous medicinal plants. Journal of Medicinal Food, v. 13, n. 2, p. 444-451, 2010.

95. AKINRINDE, A. S.; OYAGBEMI, A. A.; OMOBOWALE, T. O.; ASENUGA, E. R.; AJIBADE, T. O. Alterations in blood pressure, antioxidant status and caspase 8 expression in cobalt chloride-induced cardio-renal dysfunction are reversed by Ocimum gratissimum and gallic acid in Wistar rats. Journal of Trace Elements in Medicine and Biology, n. 36, p. 27-37, 2016.

96. HZOUNDA, J. B. F.; JAZET, P. M. D.; LAZAR, G.; RADUCANU, D.; CARAMAN, I.; BASSENE, E.; BOYOM, F. F.; LAZAR, I. M. Spectral and chemometric analyses reveal antioxidant properties ofessential oils from four Cameroonian Ocimum. Industrial Crops and Products, n. 80, p. 101-108, 2016.

97. GONTIJO, D. C.; FIETTO, L. C.; LEITE, J. P. V. Avaliação fitoquímica e atividade antioxidan e, antimutagênica e toxicológica do extrato aquoso das folhas de Ocimum gratissimum L. Revista Brasileira de Plantas Medicinais, v. 16, n. 4, p. 874-880, 2014.

98. ADETUTU, A.; OLORUNNISOLA, O. S. Hepatoprotective potential of some local medicinal plants against 2-acetylaminoflourene-induced damage in rat. Journal of Toxicology, v. 2013, p. 272097, 2013.

99. CHIU, C. C.; HUANG, C. Y.; CHEN, T. Y.; KAO, S. H.; LIU, J. Y.; WANG, Y. W.; TZANG, B. S.; HSU, T. C. Beneficial effects of Ocimum gratissimum aqueous extract on rats with $\mathrm{CCl}_{4}$-induced acute liver injury. EvidenceBased Complementary and Alternative Medicine, p. 1-9, 2012.

100. SALEMCITY, A. J.; OLADIMEJI, O.; UKWEDEH, O. E.; OLAJUYIN, A. M.; OLORUNSOGO, O. O. Methanol extract of Ocimum gratissimum leaves modulates the liver and kidney functions in $\mathrm{CCl}_{4}$ - induced hepatotoxicity in albino rats. International Journal of Pharmaceutical Sciences and Research, v. 5, n. 2, p. 36-41, 2014.

101. GEORGE, S.; CHATURVEDI, P. A comparative study of the antioxidant properties of two different species of Ocimum of Southern Africa on alcohol-induced oxidative stress. Journal of Medicinal Food, v. 12, n. 5, p. 1154 $1158,2009$.

102. GEORGE, S.; CHATURVEDI, P.; MOSEKI, B. A comparative study of therestorative effects of Ocimum gratissimum and Ocimum canum on alcohol induced hepatotoxicity in albino rats. African Journal of Food Agriculture, Nutrition and Development, v. 11, n. 7, p. 5614-5628, 2011.

103. GUPTA, A.; SHETH, N. R.; PANDEY, S.; YADAV, J. S.; JOSHI, S. V. Screening of flavonoids rich fractions of three Indian medicinal plants used for the management of liver diseases. Revista Brasileira de Farmacognosia, v. 25, n. 5, p. 485-490, 2015.

104. CHIU, Y. W.; CHAO, P. Y.; TSAI, C. C.; CHIOU, H. L.; LIU, Y. C.; HUNG, C. C.; SHIH, H. C.; LAI, T. J.; LIU, J. Y. Ocimum gratissimum is effective in prevention against liver fibrosis in vivo and in vitro. The American Journal of Chinese Medicine, v. 42, n. 4, p. 833-852, 2014.

105. ARHOGHRO, E. M.; IKEH, C.; UWAKWE, A. A.; EKPO, K. E.; ANOSIKE, E. O. Curative potential of aqueous extract of scent leaf (Ocimum gratissimum) on cisplatin induced hepatotoxicity in albino wistar rats. Journal of Pharmaceutical and Scientific Innovation, v. 1, n. 4, p. 18, 2012.

106. BORA, K. S.; SHRI, R.; MONGA, J. Cerebroprotective effect of Ocimum gratissimum against focal ischemia and reperfusion-induced cerebral injury. Pharmaceutical Biology, v. 49, n. 2, p. 175-181, 2011.

107. ALABI, Q. K.; AKOMOLAFE, R. O.; OMOLE, J. G.; ADEFISAYO, M. A.; OGUNDIPE, O. L.; ATURAMU, A.; SANYA, J. O. Polyphenol-rich extract of Ocimum gratissimum leaves ameliorates colitis via attenuating colonic mucosa injury and regulating pro-inflammatory cytokines production and oxidative stress. Biomedicine e Pharmacotherapy, n. 103, p. 812-822, 2018.

108. SAEIO, K.; CHAIYANA, W.; OKONOGI, S. Antityrosinase and antioxidant activities of essential oils of edible Thai plants. Drug Discoveries e Therapeutics, v. 5, n. 3, p. 144-149, 2011.

109. OGUANOBI, N. I.; CHIJIOKE, C. P.; GHASI, S. Anti-diabetic effect of crude leaf extracts of Ocimum 
gratissimum in neonatal streptozotocin-induced type-2 model diabetic rats. International Journal of Pharmacy and Pharmaceutical Sciences, v. 4, n. 5, p. 7783, 2012.

110. AKPAN, O. U.; BASSEY, R. B.; AGBA, B. S.; EDEGHA, I. A. Elevation of serum pancreatic amylase and distortion of pancreatic cytoarchitecture in type 1 diabetes mellitus rats treated with Ocimum gratissimum. Nigeria Medical Association, v. 55, n. 1, p. 34-38, 2014.

111. CASANOVA, L. M.; DA SILVA, D.; SOLA-PENNA, M.; DE MAGALHÃES CAMARGO, L. M.; DE MOURA CELESTRINI, D.; TINOCO, L. W.; COSTA, S. S. Identification of chicoric acid as a hypoglycemic agent from Ocimum gratissimum leaf extract in a biomonitoring in vivo study. Fitoterapia, n. 93, p. 132-141, 2014.

112. CASANOVA, L. M.; GU, W.; COSTA, S. S.; JEPPESEN, P. B. Phenolic substances from Ocimum species enhance glucose-stimulated insulin secretion and modulate the expression of key insulin regulatory genes in mice pancreatic islets. Journal of Natural Products, v. 80, n. 12, p. 3267-3275, 2017.

113. SHITTU, S. T.; OYEYEMI, W. A.; LASISI, T. J.; SHITTU, S. A.; LAWAL, T. T.; OLUJOBI, S. T. Aqueous leaf extract of Ocimum gratissimum improves hematological parameters in alloxaninduced diabetic rats via its antioxidant properties. International Journal of Applied and Basic Medical Research, v. 6, n. 2, p. 96-100, 2016.

114. TSHILANDA, D. D.; ONYAMBOKO, D. N.; BABADYBILA, P.; NGBOLUA, K. T.; TSHIBANGU, D. S.; DIA FITA DIBWE, E.; MPIANA, P. T. Antisickling activity of ursolic acid isolated from the leaves of Ocimum gratissimum L. (Lamiaceae). Natural Products and Bioprospecting, v. 5, n. 4, p. 215221, 2015.

115. DASMADHU, K.; HARINDRAN, J. Antiarthritic potential of Ocimum gratissimum L. in collagen induced arthritic Sprague-Dawley rats. Biomedicine e Aging Pathology, v. 4, n. 3, p. 191-196, 2014.

116. TANKO, Y.; MAGAJI, G. M.; YERIMA, M.; MAGAJ, R. A.; MOHAMMED, A. Antinociceptive and antiinflammatory activities of aqueous leaves extract of Ocimum gratissimum (Labiate) in rodents. African Journal of Traditional, Complementary and Alternative Medicines, v. 5, n. 2, p. 141-146, 2008. 117. ZE-LONG, J.; LEI, L.; ZI-GANG, Z.; DAN, L.; BIWEN, L.; HENG-JIN, L. Aqueous extracts of Ocimum grasstimum inhibits lipopolysaccharide-induced interleukin6 and interleukin-8 expression in airway epithelial cell BEAS-2B. Chinese Journal of Integrative Medicine, v. 19, n. 10, p. 741-748, 2013.

118. AZIBA, P. I.; BASS, D.; ELEGBE, Y. Pharmacological investigation of Ocimum gratissimum in rodents. Phytotherapy Research, v. 13, n. 5, p. 427-429, 1999.

119. KUMAR, V.; SINHA, M.; BANERJEE, A.; MOHANTY, J. Antinociceptive activity of methanolic extract of Ocimum gratissimum (Labiate) on experimental animals. International Journal of Pharmacy and Pharmaceutical Sciences, v. 3, n. 3, p. 64-66, 2011.

120. CHEN, H. M.; LEE, M. J.; KUO, C. Y.; TSAI, P. L.; LIU, J. Y.; KAO, S. H. Ocimum gratissimum aqueous extract induces apoptotic signalling in lung adenocarcinoma cell A549. Evidence-Based Complementary and Alternative Medicine, p. 1-7, 2011.

121. NANGIA-MAKKER, P.; TAIT, L.; SHEKHAR, M. P. V.; PALOMINO, E.; HOGAN, V.; PIECHOCKI, M. P.; FUNASAKA, T.; RAZ, A. Inhibition of breast tumor growth and angiogenesis by a medicinal herb: Ocimum gratissimum. International Journal of Cancer, v. 121, n. 4 , p. 884-894, 2007.

122. NANGIA-MAKKER, P.; RAZ, T.; TAIT, L.; SHEKHAR, M. P. V.; LI, H.; BALAN, V.; MAKKER, H.; FRIDMAN, R.; MADDIPATI, K.; RAZ, A. Ocimum gratissimum retards breast cancer growth and progression and is a natural inhibitor of matrix metalloproteases. Cancer Biology \& Therapy, v. 14, n. 5, p. 417-427, 2013.

123. EKUNWE, S. I. N.; HALL, S. M.; LUO, X.; WANG, H.; BEGONIA, G. B. Fractionated Ocimum gratissimum leaf extract inhibit prostate cancer $(\mathrm{PC} 3 \bullet \mathrm{AR})$ cells growth by reducing androgen receptor and survivin levels. Journal of Health Care for the Poor and Underserved, v. 24, n. 4, p. 61-69, 2013

124. LIN, C. C.; CHAO, P. Y.; SHEN, C. Y.; SHU, J. J.; YEN, S. K.; HUANG, C. Y.; LIU, J. Y. Novel target genes responsive to apoptotic activity by Ocimum gratissimum in human osteosarcoma cells. The American Journal of Chinese Medicine, v. 42, n. 3, p. 743-767, 2014.

125. OKOLI, C.; EZIKE, A.; AGWAGAH, O.; AKAH, P. Anticonvulsant and anxiolytic evaluation of leaf extracts of Ocimum gratissimum, a culinary herb. Pharmacognosy Research, v. 2, n. 1, p. 36-39, 2010.

126. IHEKWEREME, C. P.; ANIEZUE, C. M.; ERHIRHIE, E. O.; OKAFOR, U. G. Preliminary evaluation of the anti-emetic activity of crude methanol extract and fractions of Ocimum gratissimum. Journal of Developing Drugs, v. 5, n. 1, p. 1-3, 2016.

127. ONASANWO, S. A.; OMOLASO, B. O.; UKOHA, N. Ocimum grastissimum extract inhibits stimulated acid secretion by carbachol and induces gastric mucus secretion. African Journal of Medicine and Medical Sciences, n. 41, p. 35-38, 2012.

128. AGARWAL, K.; VARMA, R. Ocimum gratissimum L.: a medicinal plant with promising antiurolithiatic activity. International Journal of Pharmaceutical Sciences and Drug Research, v. 6, n. 1, p. 78-81, 2014

129. OFFIAH, V. N.; CHIKWENDU, U. A. Antidiarrhoeal effects of Ocimum gratissimum leaf extract in experimental animals. Journal of Ethnopharmacology, v. 68, n. 1-3, p. 327-330, 1999.

130. LI, P. C.; CHIU, Y. W.; LIN, Y. M.; DAY, C. H.; HWANG, G. Y.; PAI, P.; TSAI, F. J.; TSAI, C. H.; KUO, Y. C.; CHANG, H. C.; LIU, J. Y.; HUANG, C. Y. Herbal supplement ameliorates cardiac hypertrophy in rats with CCl4-induced liver cirrhosis. Evidence-Based Complementary and Alternative Medicine, p. 1-9, 2012. 131. LEE, M. J.; CHEN, H. M.; TZANG, B. S.; LIN, C. W.; WANG, C. J.; LIU, J. Y.; KAO, S. H. Ocimum gratissimum aqueous extract protects $\mathrm{H} 9 \mathrm{c} 2$ myocardiac cells from $\mathrm{H}_{2} \mathrm{O}_{2}-$ induced cell apoptosis through akt signalling. EvidenceBased Complementary and Alternative Medicine, p. 1-8, 2011.

132. MIAFO, A. T.; KOUBALA, B. B.; BOUBA, D.; KANSCI, G. Preservation of cowpea (Vigna unguiculata) seeds: incidence of ethanolic extract from Balanites aegyptiaca, Melia azedarach and Ocimum gratissimum leaves on Callosobruchus maculatus (Coleptera: Bruchidae). Asian Journal of Agricultural Research, v. 6, n. 2, p. 62-68, 2014.

133. HOCAYEN, P.A.S.; PIMENTA, D.S. Extrato de plantas medicinais como carrapaticida de Rhipicephalus (Boophilus) microplus. Revista Brasileira de Plantas Medicinais, v. 15, n. 4, p. 627-631, 2013.

134. HÜE, T.; CAUQUIL, L.; FOKOU, J. B.; DONGMO, P. M.; BAKARNGAVIA, I.; MENUT, C. Acaricidal activity of five essential oils of Ocimum species on Rhipicephalus 
(Boophilus) microplus larvae. Parasitology Research, v. 114, n. 1, p. 91-99, 2015.

135. BENOVIT, S. C.; GRESSLER, L. T.; de LIMA SILVA, L.; de OLIVEIRA GARCIA, L. O.; OKAMOTO, M. H.; dos SANTOS PEDRON, J. S.; SAMPAIO, L. A.; RODRIGUES, R. V.; HEINZMANN, B. M.; BALDISSEROTTO, B. Anesthesia and transport of brazilian flounder, Paralichthys orbignyanus, with essential oils of Aloysia gratissima and Ocimum gratissimum. Journal of the World Aquaculture Society, v. 43, n. 6, p. 896-900, 2012.

136. LIMA, A. S.; MILHOMEM, M. N.; MONTEIRO, O. S.; ARRUDA, A. C. P.; DE CASTRO, J. A. M.; FERNANDES, Y. M. L.; MAIA, J. G. S.; COSTA-JUNIOR, L. M. Seasonal analysis and acaricidal activity of the thymol-type essential oil of Ocimum gratissimum and its major constituents against Rhipicephalus microplus (Acari: Ixodidae). Parasitology Research, v. 117, n. 1, p. 59-65, 2018.

137. BOIJINK, C. L.; QUEIROZ, C. A.; CHAGAS, E. C.; CHAVES, F. C. M.; INOUE, L. A. K. A. Anesthetic and anthelminthic effects of clove basil (Ocimum gratissimum) essential oil for tambaqui (Colossoma macropomum). Aquaculture, n. 457, p. 24-28, 2016.

138. RIBEIRO, A. S.; BATISTA, E. D. S.; DAIRIKI, J. K.; CHAVES, F. C. M.; INOUE, L. A. K. A. Anesthetic properties of Ocimum gratissimum essencial oil for juvenile matrinxã. Acta Scientiarum, v. 38, n. 1, p. 1-7, 2016. 139. BRUM, A.; CARDOSO, L.; CHAGAS, E. C.; CHAVES, F. C. M.; MOURIÑO, J. L. P.; MARTINS, M. L. Histological changes in Nile tilapia fed essential oils of clove basil and ginger after challenge with Streptococcus agalactiae. Aquaculture, n. 490, p. 98-107, 2018.

140. KOUNINKI, H.; NGAMO, L. S. T.; HANCE, T.; NGASSOUM, M. B. Potential use of essential oils from local Cameroonian plants for the control of red flour weevil Tribolium castaneum (Herbst.) (Coleoptera: Tenebrionidae). African Journal of Food Agriculture, Nutrition and Development, v. 7, n. 5, 2007.

141. KOUBALA, B. B.; MIAFO, A. T.; BOUBA, D.; KAMDA, A. G. S.; KANSCI, G. Evaluation of insecticide properties of ethanolic extract from Balanites aegyptiaca, Melia azedarach and Ocimum gratissimum leaves on Callosobruchus maculatus (Coleptera: Bruchidae). Asian Journal of Agricultural Research, v. 5, n. 5, p. 93-101, 2013.

142. BERNARDES, W. A.; SILVA, E. O.; CROTTI, A. E. M.; BALDIN, E. L. L. Bioactivity of selected plant-derived essential oils against Zabrotes subfasciatus (Coleoptera: Bruchidae). Journal of Stored Products Research, n. 77, p. 16-19, 2018

143. LAHLOU, S.; INTERAMINENSE, F. L. F.; LEALCARDOSO, J. H.; MORAIS, S. M.; DUARTE, G. P. Cardiovascular effects of the essential oil of Ocimum gratissimum leaves in rats: role of the autonomic nervous system. Clinical and Experimental Pharmacology and Physiology, v. 31, n. 4, p. 219-225, 2004.

144. FREIRE, C. M. M.; MARQUES, M. O. M.; COSTA, $M$. Effects of seasonal variation on the central nervous system activity of Ocimum gratissimum L. essential oil. Journal of Ethnopharmacology, v. 105, n. 1-2, p. 161-166, 2006.

145. GAliNDO, L. A.; PULTRINI, A. M.; COSTA, M. Biological effects of Ocimum gratissimum L. are due to synergic action among multiple compounds present in essential oil. Journal of Natural Medicines, v. 64, n. 4, p. 436-441, 2010.

146. IBIRONKE, G. F.; MODUPE, O. G. Non cholinergic dependent mechanism of Ocimum gratissimum induced neurobehavioural alterations in mice. African Journal of Medicine and Medical Sciences, v. 44, n. 3, p. 213-220, 2015.

147. OFEM, O. E.; ANI, E. J.; ENO, A. E. Effect of aqueous leaves extract of Ocimum gratissimum on hematological parameters in rats. Indian Journal of Basic and Applied Medical Research, v. 2 , n. 1, p. $38-42,2012$

148. IWEALA, E. E. J.; OBIDOA, O. Studies on some biochemical and histological changes associated with long term consumption of leaves of Ocimum gratissimum L. in male rats. American Journal of Food Technology, v. 5, n. 6, p. 376-384, 2010.

149. THOMAS, J. M.; VARKEY, J.; AUGUSTINE, B. B. Association between serum cholesterol, brain serotonin, and anxiety: A study in simvastatin administered experimental animals. International Journal of Nutrition, Pharmacology and Neurological Diseases, v. 4, n. 1, p. 6973, 2014

150. OBIANIME, A. W.; APRIOKU, J. S.; ESOMONU, C. T. O. Antifertility effects of aqueous crude extract of Ocimum gratissimum L. leaves in male mice. Journal of Medicinal Plants Research, v. 4, n. 9, p. 809-816, 2010. 151. SRIPRIYA, S; YUVARAJ, G; NEMA, R. K.; KUMAR, V. M.; DEECARAMAN, M. Evaluation of antifertility activity from stem part of Ocimum gratissimum in acetone extracts. International Journal of Pharmaceutical and Clinical Research, n. 3, p. 41-44, 2011.

152. EGBA, S. I.; OMODAMIRO, O. D.; OBIKE, J. C.; ALI, E. S. Influence on some female fertility hormonal response in wistar albino rats: possible contraceptive role for methanol leaf extract of Ocimum gratissimum? Journal of Chemical and Pharmaceutical Research, v. 7, n. 5, p. 889898, 2015.

153. AKINBORO, A.; BAKAREB, A. A. Spermatotoxic, cytotoxic and genotoxic evaluation of aqueous extract of Ocimum gratissimum in albino mice. Journal of Medicinal and Aromatic Plants, v. 4, n. 1, p. 10-14, 2013.

154. HERNÁNDEZ, N. B.; RUIZ, A. R.; PARRA, A. V. Evaluación tóxica y genotóxica del extracto fluido de Ocimum gratissimum L. Revista Cubana de Plantas Medicinas, v. 11, n. 1, p. 1-8, 2006.

155. OLABANJI, S. O.; ADEBAJO, A. C.; OMOBUWAJO, O. R.; CECCATO, D.; BUOSO, M. C.; MOSCHINI, G. PIXE analysis of some Nigerian antidiabetic medicinal plants (II). Nuclear Instruments and Methods in Physics Research, v. 318, n. A, p. 187-190, 2014.

156. FANDOHAN, P.; GNONLONFIN, B.; LALEYE, A.; GBENOU, J. D.; DARBOUX, R.; MOUDACHIROU, M. Toxicity and gastric tolerance of essential oils from Cymbopogon citratus, Ocimum gratissimum and Ocimum basilicum in Wistar rats. Food and Chemical Toxicology, v. 46, n. 7, p. 2493-2497, 2008

157. AGUIAR, J. J. S.; SOUSA, C. P. B.; ARARUNA, M.

K. A.; SILVA, M. K. N.; PORTELO, A. C.; LOPES, J. C.; CARVALHO, V. R. A.; FIGUEREDO, F. G.; BITU, V. C. N.; COUTINHO, H. D. M.; MIRANDA, T. A. S.; MATIAS,

E. F. F. Antibacterial and modifying-antibiotic activities of the essential oils of Ocimum gratissimum L. and Plectranthus amboinicus L. European Journal of Integrative Medicine, v. 7, n. 2, p. 151-156, 2015. 